\title{
DETERMINATION OF QUERCETIN AND RUTIN IN THE ETHYL ACETATE FRACTION OF Etlingera elatior (JACK) R.M. SMITH FLOWER BY REVERSED-PHASE LIQUID CHROMATOGRAPHY-MASS SPECTROSCOPY
}

\author{
M. Mutakin ${ }^{1}$, T. Juwita ${ }^{2}$, S. Megantara ${ }^{1}$, I. M. Puspitasari ${ }^{2}$ and J. Levita ${ }^{2, *}$ \\ ${ }^{1}$ Department of Pharmaceutical Analysis and Medicinal Chemistry, Universitas Padjadjaran, \\ Sumedang-45363, (West Java) Indonesia \\ ${ }^{2}$ Department of Pharmacology and Clinical Pharmacy, Universitas Padjadjaran, Sumedang- \\ 45363, (West Java) Indonesia \\ *E-mail: jutti.levita@unpad.ac.id
}

\begin{abstract}
Etlingera elatior (Jack) R.M. Smith (Zingiberaceae), has been reported to possessing various pharmacological activities. Secondary metabolites, e.g. kaempferol-3-O-glucoside, kaempferol, and quercetin have been identified within the flower. Our work determined the flavonol content, e.g. quercetin and rutin in particular, in the ethyl acetate fraction of E. elatior flower. Initially, the flowers were macerated with $70 \%$ ethanol at $29^{\circ} \mathrm{C}$ for $3 \times 24$ hours and filtered. The filtrates were collected and rotary-evaporated at $65 \mathrm{rpm}$ (equals to 20440 relative centrifugal force) $45^{\circ} \mathrm{C}$ and the resulted E. elatior flower viscous extract was subjected to spectrophotometric identification and liquidliquid partitioned using ethyl acetate. For identifying the flavonols, shift reagents (aluminium chloride and sodium acetate) were used. The ethyl acetate fraction was injected separately into an octadecylsilane column $(1.7 \mu \mathrm{m} ; 2.1 \mathrm{x}$ $100 \mathrm{~mm}$ ) of liquid chromatography-mass spectroscopy. Mobile phase employed was a mixture of double-distilled water $99.9 \%$ and formic acid $0.1 \%$; at a flow rate of $0.2 \mathrm{~mL} / \mathrm{minute}$; source temperature $100^{\circ} \mathrm{C}$; desolvation temperature $350^{\circ} \mathrm{C}$; cone gas flow $15 \mathrm{~L}$ of nitrogen/hour. Based on the retention profile and mass fragmentation, quercetin (retention time at 7.94 minutes; $\mathrm{m} / \mathrm{z}$ 301.1423) and rutin (retention time at 5.97 minutes; $\mathrm{m} / z$ 609.2082) were detected in the ethyl acetate fraction with the former's concentration $1.16 \% w / w$ and the latter's $0.61 \% w / w$.
\end{abstract}

Keywords: Anti-inflammation, E. elatior, Flavonols, LC-MS, Quercetin, Rutin, Zingiberaceae

(C) RASĀYAN. All rights reserved

\section{INTRODUCTION}

Etlingera elatior (Jack) R.M. Smith (Zingiberaceae), has been reported to possessing various pharmacological activities, which might be contributed by its metabolites content. Secondary metabolites, e.g. kaempferol-3-O-glucoside, kaempferol, and quercetin, have been identified within the flower. ${ }^{1}$ Moreover, essential oils were abundantly found in all parts of the plants, mostly contains monoterpenes hydrocarbons. Miscellaneous compounds were quantified more in the flowers. ${ }^{2}$ Diverse methods to determine quercetin (Fig.-1a) and/or rutin (Fig.-1b) in plants have been reported, e.g. reversed phase-high performance liquid chromatography (RP-HPLC) by employing various mobile phases, ${ }^{3-10}$ highperformance thin layer chromatography (HPTLC), ${ }^{7,8,10}$ and ultraviolet-visible spectrophotometry. ${ }^{411}$ None of those studies reported on the determination of quercetin and rutin by liquid chromatographytandem mass spectroscopy (LC-MS), therefore, our work determined quercetin and rutin in the ethyl acetate fraction of E. elatior (Jack) R.M. Smith flower by using reversed-phase LC-MS method.

\section{EXPERIMENTAL}

\section{Instruments}

Instruments utilized in this work were: rotary evaporator (IKA 0010000403 RV8 with dry ice condenser), liquid chromatography (Waters AcquityTM Ultra Performance LC) in tandem with mass spectroscopy (Waters Xevo ${ }^{\mathrm{TM}}$ QTof MS) instrument and chemical glassware.

Rasayan J. Chem., 13(3), 1379-1385(2020)

http://dx.doi.org/10.31788/RJC.2020.1335723

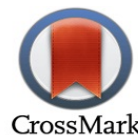


RASĀYAN J. Chem.

Vol. 13 | No. 3 |1379-1385| July - September | 2020<smiles>O=c1c(O)c(-c2ccc(O)c(O)c2)oc2cc(O)cc(O)c12</smiles>

(a)<smiles>C[C@@H]1OC(OCC2O[C@H](Oc3c(-c4ccc(O)c(O)c4)oc4cc(O)cc(O)c4c3=O)[C@H](O)[C@H](O)[C@H]2O)[C@H](O)[C@@H](O)[C@@H]1O</smiles>

(b)

Fig.-1: Chemical Structure of (a) Quercetin $\left(\mathrm{C}_{15} \mathrm{H}_{12} \mathrm{O}_{8}\right.$; ChemSpider ID 12269344) and (b) Rutin $\left(\mathrm{C}_{27} \mathrm{H}_{30} \mathrm{O}_{16}\right.$; ChemSpider ID 4444362)

\section{Chemicals and Plant Materials}

The fresh plant and flowers of E. elatior were purchased from Bumi Herbal, Bandung, West Java, Indonesia (http://bumiherbal.com/). The plant was taxonomically identified at the Laboratory of Plant Taxonomy, Department of Biology, Faculty of Mathematics and Natural Sciences, Universitas Padjadjaran, West Java, Indonesia (Document No. 198/HB/10/2018). Quercetin hydrate standard 96\% purity (Tokyo Chemical Industry Co., Ltd. CAS 849061-97-8 Product P0042) and rutin hydrate 98\% purity (Tokyo Chemical Industry Co., Ltd. CAS 207671-50-9 Product R0035) were purchased from PT Indogen Intertama/Quartiz Indonesia (http://indogen.id/).

\section{Preparation of the E. elatior (Jack.) R.M. Smith Flower Extract (EFE) and the Ethyl Acetate Fraction (EFEAF)}

Fresh E. elatior flowers were cleaned and washed under tap-water, then were oven-dried at $50^{\circ} \mathrm{C}$ for 2 hours. Dried flowers were sliced into small pieces and soaked $(400 \mathrm{~g})$ in $70 \%$ ethanol in a macerator at room temperature for $3 \times 24$ hours and filtered. The filtrates were collected and evaporated using a rotary evaporator at $45^{\circ} \mathrm{C} 65 \mathrm{rpm}$ (20440 relative centrifugal force or rcf) and the resulted viscous extract (EFE) was subjected to spectrophotometric identification and liquid-liquid partition using ethyl acetate. The obtained ethyl acetate fraction (EFEAF) was stored for further use.

\section{Identification of Flavonols in the EFE by Using a Spectrophotometric Method}

Standard solutions of quercetin (CAS 849061-97-8) and rutin (CAS 207671-50-9) were also prepared by dissolving $50 \mathrm{mg}$ of the compound in $250 \mathrm{~mL}$ of an analytical grade of ethanol. These standard solutions were diluted to obtain $10 \mu \mathrm{g} / \mathrm{mL}$ concentration. An equimolar of $10 \%$ aluminium chloride $\left(\mathrm{AlCl}_{3}\right)$ and sodium acetate $\left(\mathrm{CH}_{3} \mathrm{COONa}\right)$ were added to the solutions. The mixtures were scanned in an ultravioletvisible spectrophotometer (Specord 200; Analytikjena) against ethanol to obtain the $\lambda_{\max }$ of quercetin and rutin.

Accurately weighed $50 \mathrm{mg}$ of EFE was dissolved in $250 \mathrm{ml}(200 \mu \mathrm{g} / \mathrm{ml})$ of analytical grade ethanol. An equimolar of $10 \%$ aluminium chloride $\left(\mathrm{AlCl}_{3}\right)$ and sodium acetate $\left(\mathrm{CH}_{3} \mathrm{COONa}\right)$ were added to the solutions to confirm the presence of flavonoids. The solution was scanned in an ultraviolet-visible spectrophotometer (Specord 200; Analytikjena) against ethanol.

\section{Determination of Quercetin and Rutin in the EFEAF by Using LC-MS Method}

Various concentrations of standard quercetin $(20 ; 40 ; 60 ; 80$; and $100 \mu \mathrm{g} / \mathrm{mL})$ and rutin $(20 ; 40 ; 60 ; 80$; and $100 \mu \mathrm{g} / \mathrm{mL}$ ) were Millipore-filtered. $5 \mu \mathrm{L}$ of each solution was injected separately into Acquity ${ }^{\mathrm{TM}}$ Ultra Performance LC BEH Shield RP18 $1.7 \mu \mathrm{m} ; 2.1$ x 100 mm Column (Part No. 186002352 Serial No. 
RASĀYAN J. Chem.

Vol. 13 | No. 3 |1379-1385| July - September | 2020

018530238157 19) of LC-MS (Waters AcquityTM Ultra Performance LC and Waters Xevo ${ }^{\text {TM }}$ QTof MS) to obtain the standard curves of quercetin and rutin. Mobile phase employed was a mixture of $\mathrm{H}_{2} \mathrm{O} 99.9 \%$ and formic acid $0.1 \%$; at flow rate $0.2 \mathrm{~mL} /$ minute; source temperature $100^{\circ} \mathrm{C}$; desolvation temperature $350^{\circ} \mathrm{C}$; cone gas flow $15 \mathrm{~L}$ of nitrogen/hour.

Accurately weighed $0.3138 \mathrm{~g}$ of EFEAF was dissolved in $25 \mathrm{~mL}$ of analytical grade ethanol. The solution was Millipore-filtered and injected into Acquity ${ }^{\mathrm{TM}}$ Ultra Performance LC BEH Shield RP18 $1.7 \mu \mathrm{m} ; 2.1 \mathrm{x}$ $100 \mathrm{~mm}$ Column (Part No. 186002352 Serial No. 018530238157 19) of LC-MS (Waters AcquityTM Ultra Performance LC and Waters Xevo ${ }^{\mathrm{TM}}$ QTof MS). A similar condition with the standards was employed.

\section{RESULTS AND DISCUSSION}

In this work, we determined quercetin and rutin in the ethyl acetate fraction of Etlingera elatior (Jack) R.M. Smith flower by reversed-phase liquid chromatography-mass spectroscopy. The extraction was carried out by a cold method to prevent the degradation of the secondary metabolites. ${ }^{12}$ The viscous extract yielded was $35.8 \mathrm{~g}(8.95 \% \mathrm{w} / \mathrm{w})$.

The spectra of standard quercetin (Fig.-2a) and rutin (Fig.-2b) in ethanol show two maxima which belong to cinnamoyl (the band I at $374 \mathrm{~nm}$ for quercetin and $361 \mathrm{~nm}$ for rutin) and benzoyl (the band II at 255 $\mathrm{nm}$ for quercetin and $262 \mathrm{~nm}$ for rutin).

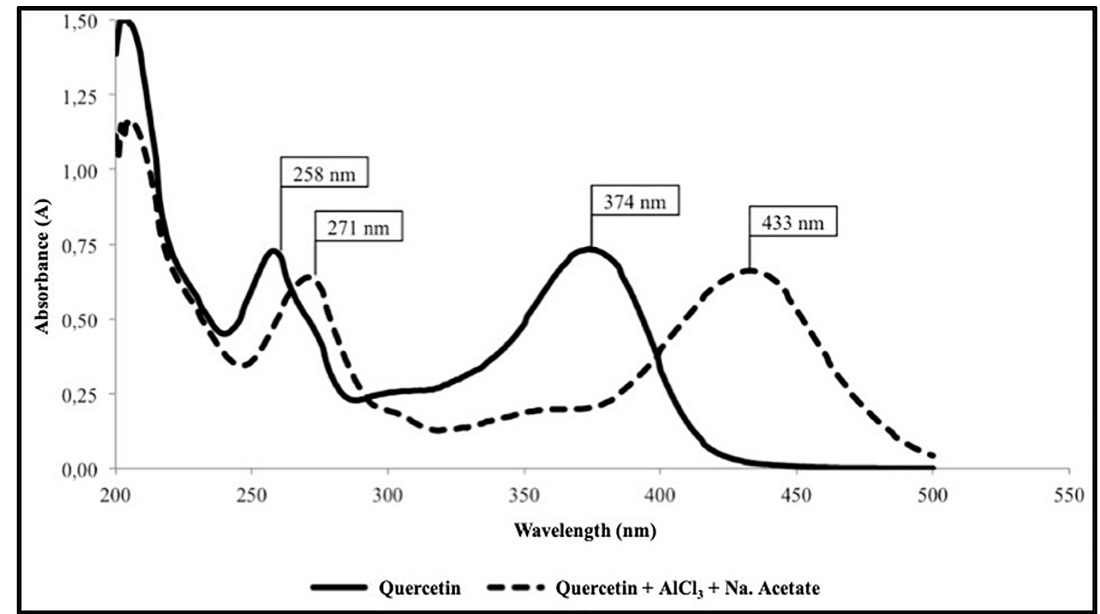

(a)

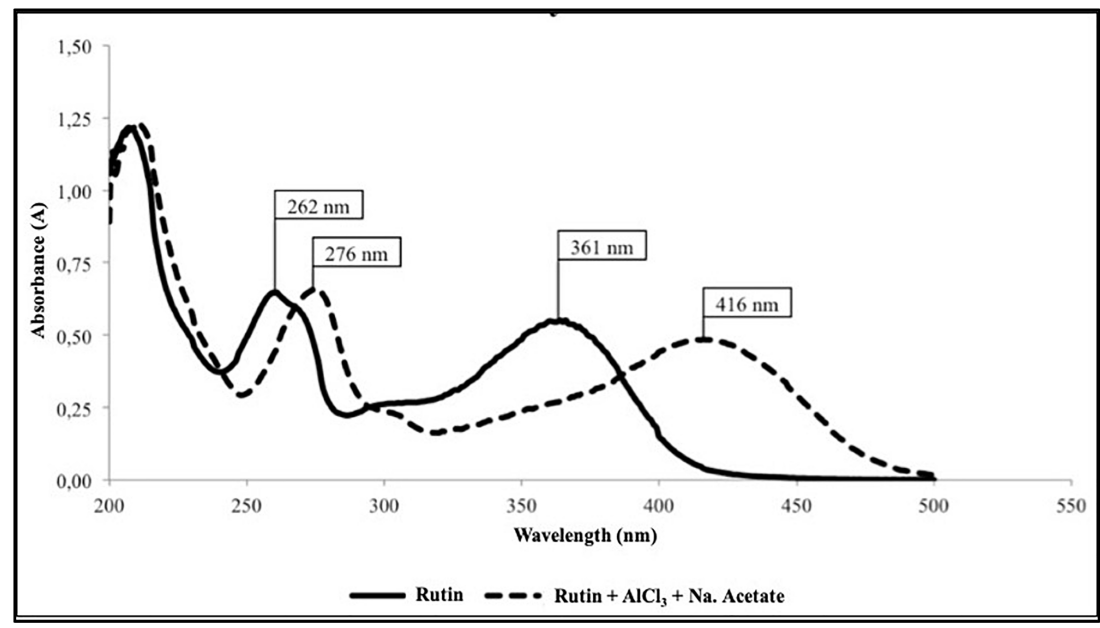

(b)

Fig.-2: Ultraviolet Spectra of Standard (a) Quercetin and (b) Rutin. Dashed Lines indicate the Bathochromic Shift of the Maxima after the Addition of $\mathrm{AlCl}_{3}-\mathrm{CH}_{3} \mathrm{COONa}$ 
RASĀYAN J. Chem.

Vol. 13 | No. 3 |1379-1385| July - September | 2020

Bathochromic shift (redshift) has resulted in the addition of $\mathrm{AlCl}_{3}-\mathrm{CH}_{3} \mathrm{COONa}$ to the standard solutions, which indicates the formation of flavonoid-aluminium complex. ${ }^{13}$ This shift to longer wavelength (5-20 $\mathrm{nm}$ in band II) is caused by the weak base character of sodium acetate, which reacts with 7-OH in flavonols. However, a shoulder peak in the band I, which is often observed, may lead to obscureness in identifying $3^{\prime}$ - or $4^{\prime}-\mathrm{OH}$ of flavones or flavonols. ${ }^{14}$ Three sites (one dihydroxyl in the B ring and two sites comprises of hydroxyl and carbonyl in the $\mathrm{C}$ ring) in the molecule of flavonoid are considered capable to interact with aluminium or other Lewis acid cation. ${ }^{15}$

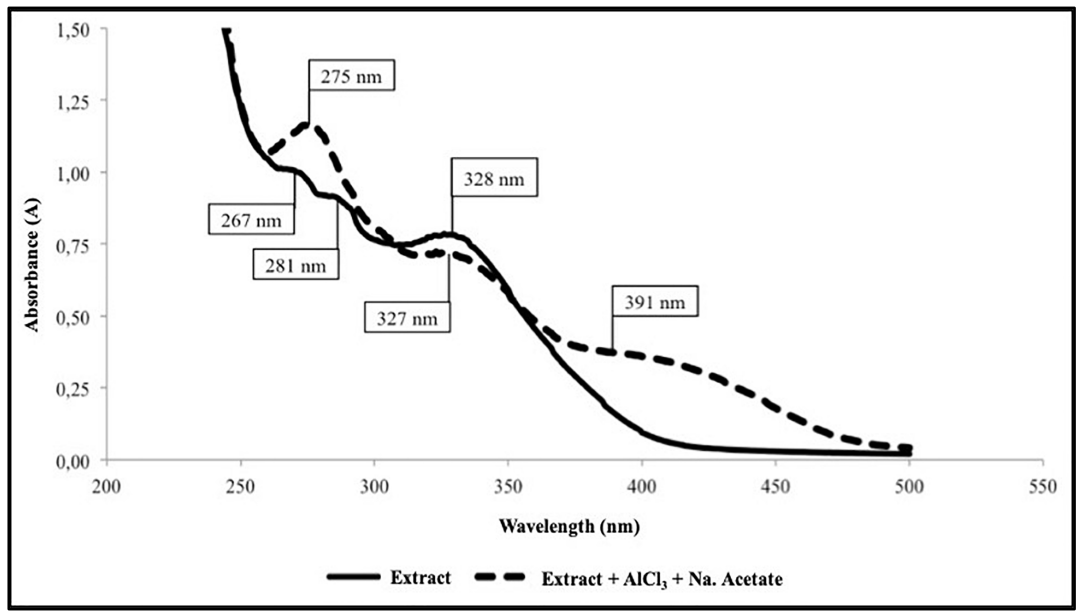

Fig.-3: UV Absorption Spectra of EFE. Dashed Lines indicate the Bathochromic Shift of the Maxima after the Addition of $\mathrm{AlCl}_{3}-\mathrm{CH}_{3} \mathrm{COONa}$

The extraction of flavonoids is often performed by employing polar solvents, either alone or in combination. ${ }^{16}$ The UV absorption spectrum of EFE (Fig.-3) reveals three maxima at $267 \mathrm{~nm}$ (the band II), $281 \mathrm{~nm}$ (shoulder peak), and $328 \mathrm{~nm}$ (the band I) which confirms the presence of flavonoids. A bathochromic shift of band II ( $267 \mathrm{~nm} \rightarrow 275 \mathrm{~nm}$; indicated by dashed lines in Fig.-3) was also taken place after the addition of $\mathrm{AlCl}_{3}-\mathrm{CH}_{3} \mathrm{COONa}$.

The LC chromatogram of the standards (Fig.-4a) conveys two distinct peaks, i.e. rutin $\left(t_{R}=5.94\right.$ minutes) and quercetin $\left(t_{R}=7.93\right.$ minutes), respectively, which indicates good separation and detection. Rutin was eluted faster due to its glycosides which contributes to its polarity. Likewise, the LC chromatogram of EFEAF (Fig.-4b) also indicates the presence of rutin ( $t_{R}=5.97$ minutes) and quercetin $\left(t_{R}=7.94\right.$ minutes). The concentration of these two flavonols, calculated using the standard curve of quercetin $(y=$ $\left.107.76 x+183.6 ; \mathrm{R}^{2}=0.9996\right)$ and rutin $\left(y=257.97 x+462.6 ; \mathrm{R}^{2}=0.9978\right)$, are $1.16 \% w / w$ and $0.61 \%$ $w / w$. respectively.

Our work was compared to that of Chang and co-workers (2012), who reported that flavonoids were quantified in Costus speciosus and Etlingera elatior using reversed-phase LC-MS with a binary mobile phase under gradient elution conditions. ${ }^{1}$ However, previous studies of Chang and co-workers (2012) and Ghasemzadeh and co-workers (2015) reported that the flavonols contained within E. elatior flowers planted on various locations in Malaysia were $0.019 \%(w / v)^{1}$ and $7.996 \%(w / v),{ }^{17}$ respectively. Flavonoids have been reported found in coloured (yellow, red, orange, blue, or purple) plants. These secondary metabolites could be extracted from the plant parts (fruit, flower, or leaves). ${ }^{18}$ The chemical structures of quercetin and rutin contain chromophores (aromatic rings) and auxochromes (hydroxyls directly attached to the chromophores). ${ }^{19}$ Thus, these compounds can absorb electromagnetic radiation in the UV region at $374 \mathrm{~nm}$ for quercetin and $361 \mathrm{~nm}$ for rutin.

The positive electrospray ionization time-of-flight mass spectrometry (TOF MS ES+) analysis reveals that quercetin (a medium peak fragmented at $\mathrm{m} / \mathrm{z}$ 301.1423; Fig.-5c) and rutin (a strong peak at $\mathrm{m} / \mathrm{z}$ 609.2082; Fig.-5d) were present in EFEAF, which were similarly compared to the standards (quercetin $\mathrm{m} / \mathrm{z} 301.1407$ in Fig.-5a and rutin $m / z$ 609.2000 in Fig.-5b ). 
RASĀYAN J. Chem.

Vol. 13 | No. 3 |1379-1385| July - September | 2020

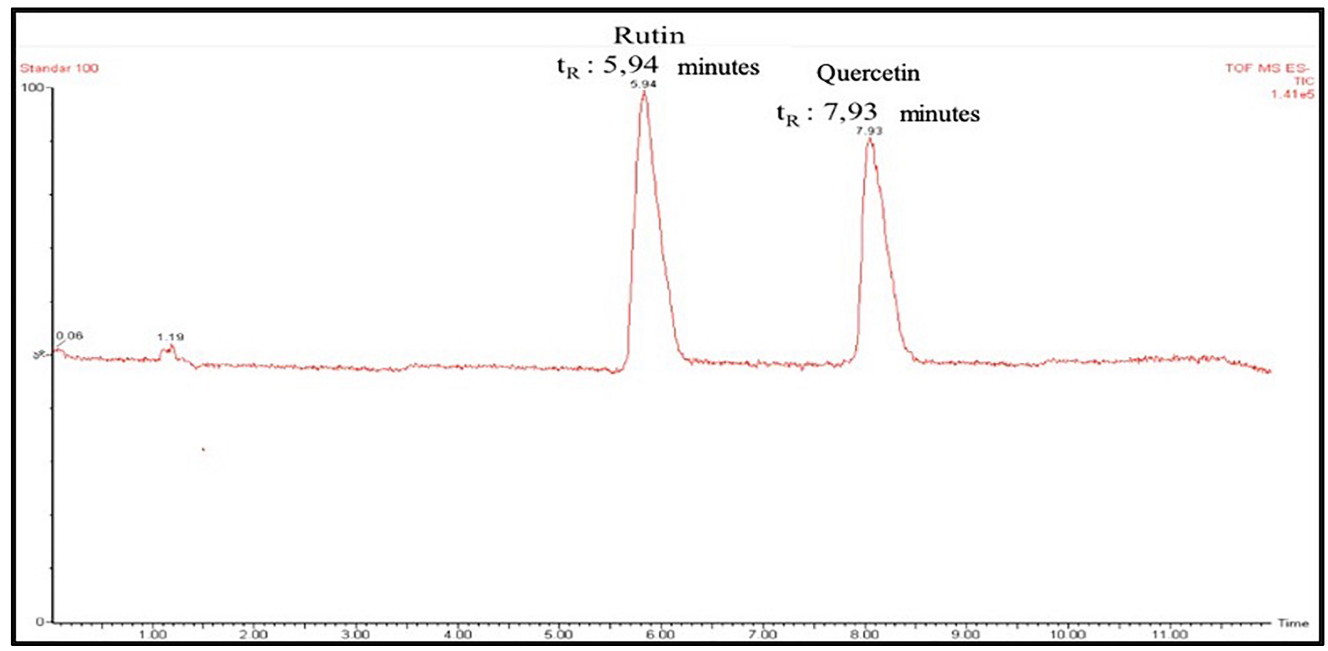

(a)

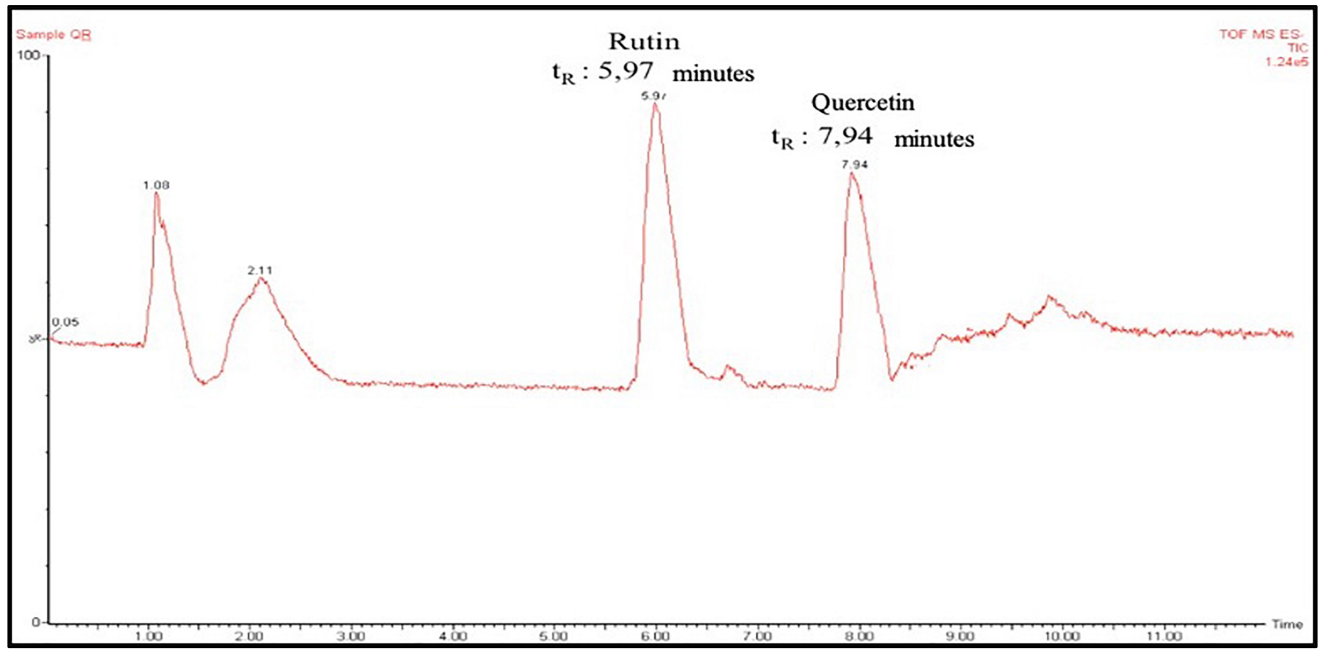

(b)

Fig.-4: LC Chromatogram of (a) Standard Quercetin and Rutin in Ethanol; (b) Quercetin and Rutin in EFEAF

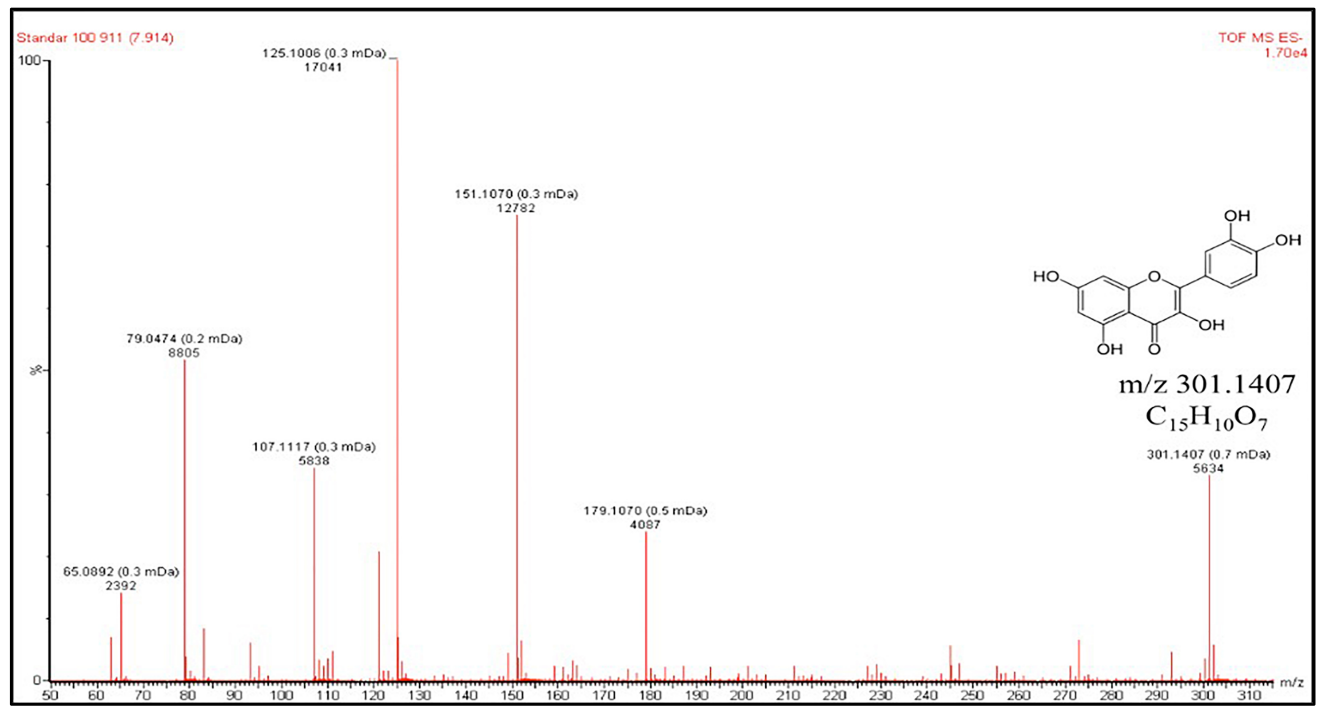

(a) 
RASĀYAN J. Chem.

Vol. 13 | No. 3 |1379-1385| July - September | 2020

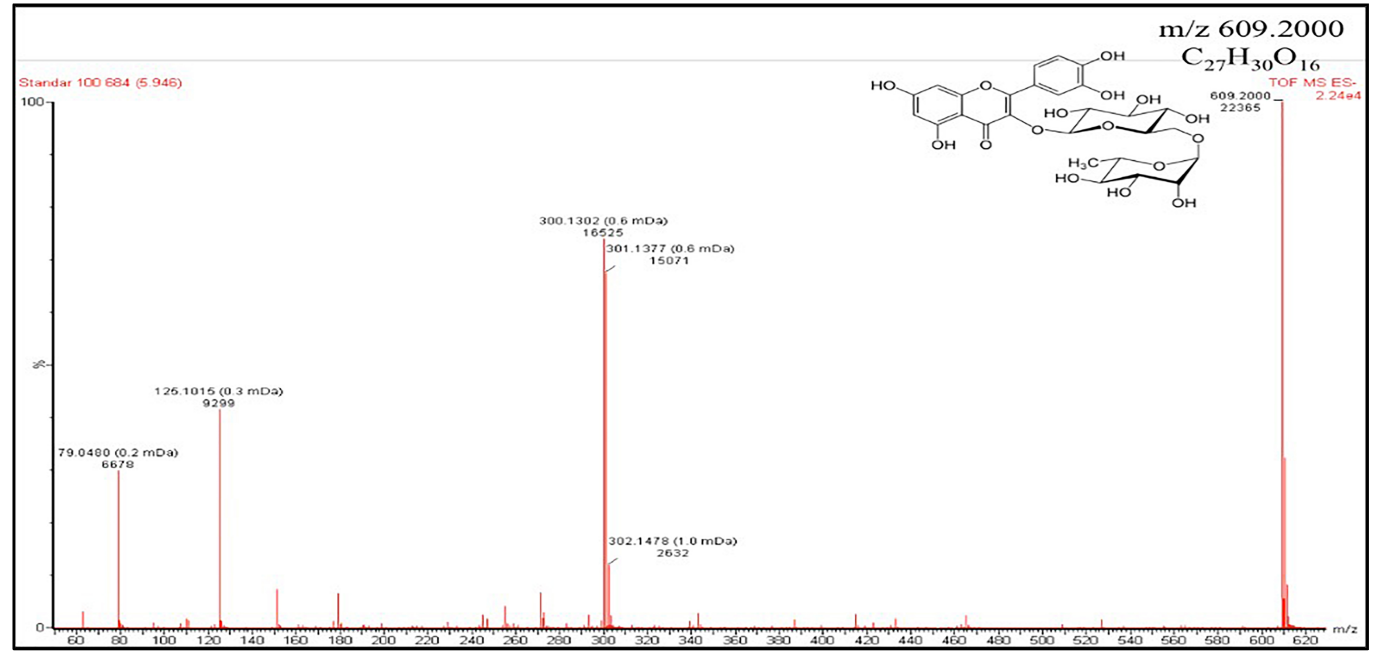

(b)

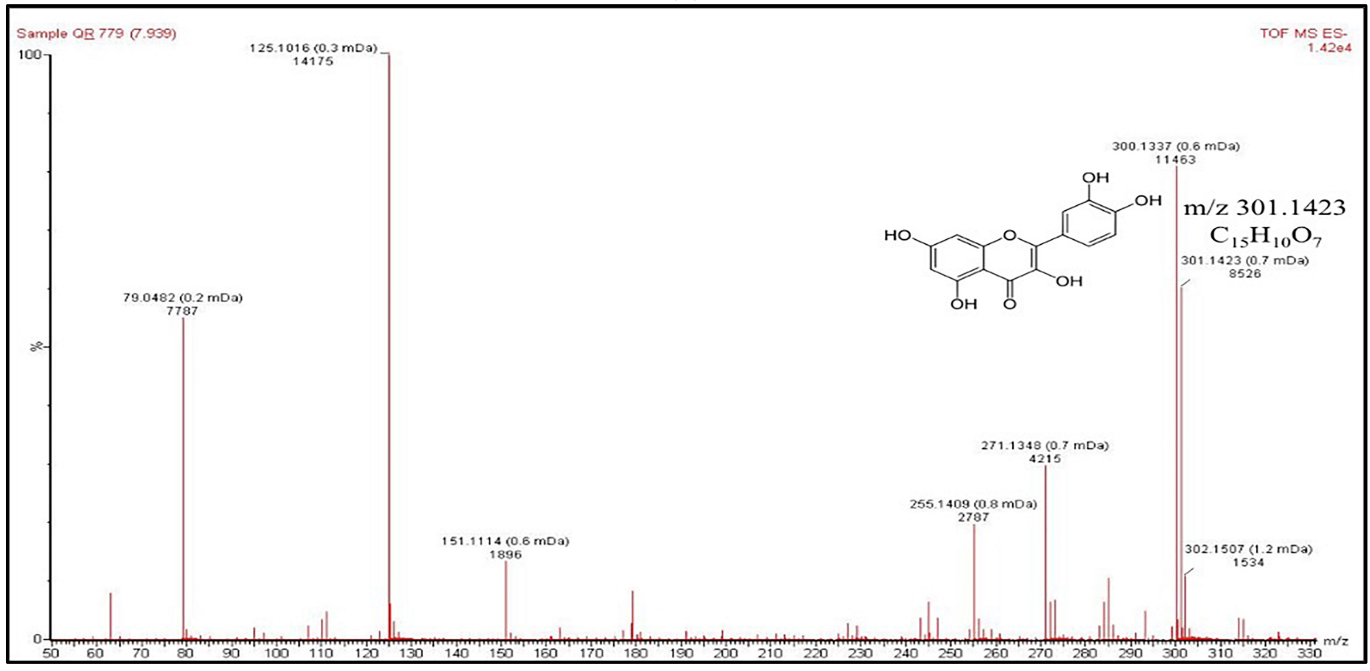

(c)

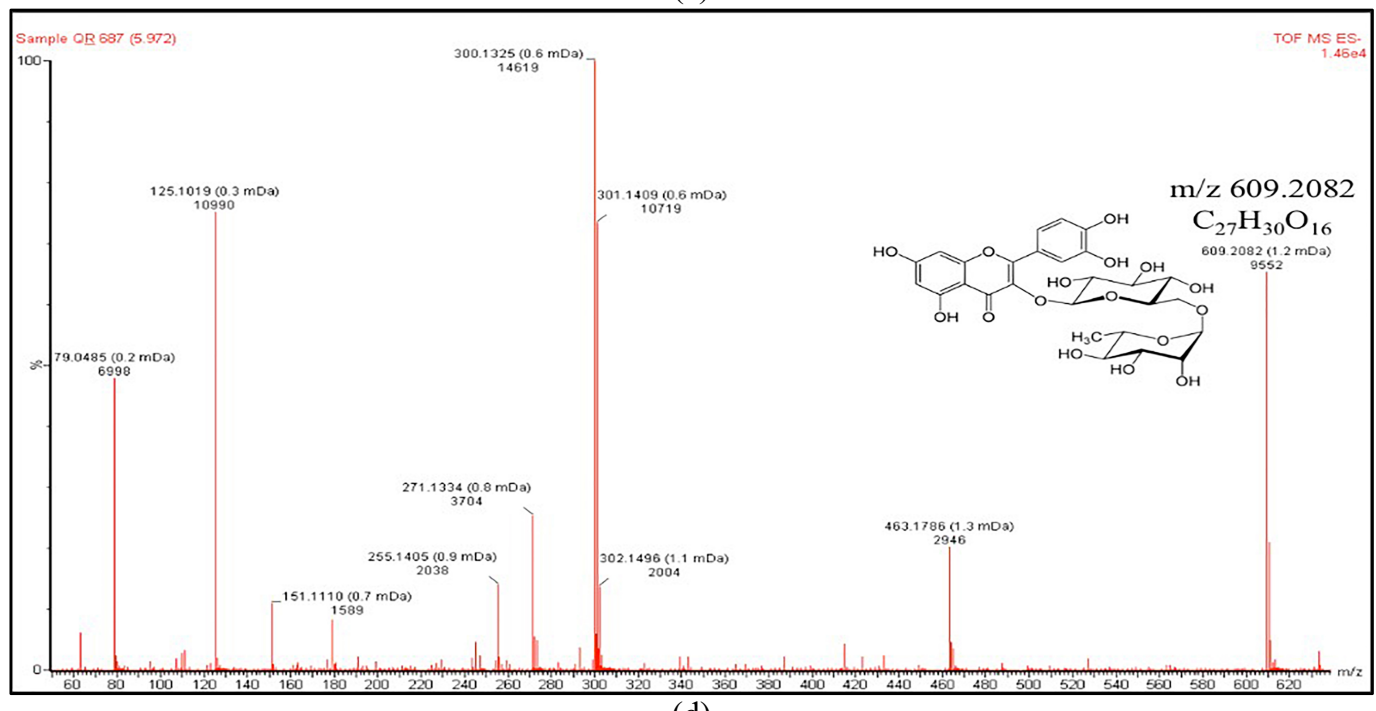

(d)

Fig.-5: The TOF MS ES+ Spectra of (a) Standard Quercetin; (b) Standard Rutin; (c) Quercetin in EFEAF; and (d) Rutin in EFEAF 
RASĀYAN J. Chem.

Vol. 13 | No. 3 |1379-1385| July - September | 2020

\section{CONCLUSION}

We concluded that at least two flavonols, namely quercetin, and rutin, are present in a small amount in the flower of Etlingera elatior. The UV absorption spectrum of the ethanol extract revealed three maxima at $267 \mathrm{~nm}$ (the band II), $281 \mathrm{~nm}$ (shoulder peak), and $328 \mathrm{~nm}$ (the band I). The positive electrospray ionization time-of-flight mass spectrometry (TOF MS ES+) analysis also confirmed the presence of these two flavonols (quercetin at $\mathrm{m} / \mathrm{z} 301.1423$ and rutin at $\mathrm{m} / \mathrm{z}$ 609.2082).

\section{ACKNOWLEDGMENT}

The authors would like to thank the Rector of Universitas Padjadjaran Indonesia for facilitating and supporting this project via the Academic-Leadership Grant of Universitas Padjadjaran. The publication fee is funded by Universitas Padjadjaran via the Directorate of Research and Community Engagement (DRPM) Universitas Padjadjaran 2020.

\section{REFERENCES}

1. Y.Q. Chang, S.N. Tan, J.W.H. Yong and L. Ge, Analytical Letters, 45(4), 345(2012), DOI: $10.1080 / 00032719.2011 .644740$

2. F.M. Jaafar, C.P. Osman, N.H. Ismail and K. Awang, Malaysian Journal of Analytical Science, 11(1), 267(2007)

3. M. Biesaga and K. Pyrzynska, Critical Reviews in Analytical Chemistry, 39(2), 95(2009), DOI: $10.1080 / 10408340902820718$

4. M. Kurzawa, Analytical Letters, 43(6), 893(2010), DOI:10.1080/00032710903491070

5. H. Bojarowicz, M.P. Marszałł, M. Wnuk, K. Goryński and A. Buciński, Analytical Letters, 44(9), 1728(2011), DOI:10.1080/00032719.2010.526262

6. Y. He, Z. He, F. He and H. Wan, Pharmacognosy Magazine, 8(32), 263(2012), DOI:10.4103/09731296.103649

7. G.M. Doshi, S.P. Zine, P.K. Chaskar and H.D. Une, Pharmacognosy Research, 6(3), 234(2014), DOI: $10.4103 \% 2 F 0974-8490.132601$

8. G.M. Doshi and H.D. Une, Pharmacognosy Research, 8(1), 37(2016), DOI:10.4103/09748490.171098

9. M. Yue-ling, C. Yu-jie, W. Ding-rong, C. Ping and X. Ran, Pharmacognosy Journal, 9(6), 725(2017)

10. P. Alam, M.K. Parvez, A.H. Arbab and M.S. Al-Dosari, Pharmaceutical Biology, 55(1), 1317(2017), DOI: $10.1080 \% 2 \mathrm{~F} 13880209.2017 .1300175$

11. H. Xu, Y. Li, H-W. Tang, C-M. Liu and Q-S Wu, Analytical Letters, 43(6), 993(2010), DOI: $10.1080 / 00032710903488795$

12. M.N. Moraes, G.L. Zabot, J.M. Prado and M.A.A. Meireles, Food and Public Health, 3(4), 195(2013), DOI:10.5923/j.fph.20130304.04.

13. D.N. Azizah, E. Kumolowati and F. Faramayuda, Kartika Jurnal Ilmiah Farmasi, 2(2), 45(2014)

14. R. Colombo, J.H. Yariwake, E.F. Queiroz, K. Ndjoko and K. Hostettmann, Phytochemical Analysis, 17, 337(2006), DOI: 10.1002/pca.923

15. D. Malešev and V. Kuntic, Journal of Serbian Chemical Society, 72(10), 921(2007)

16. J.Y. Qian, D. Liu and A.G. Huang, Food Chemistry, 87, 283(2004)

17. A. Ghasemzadeh, H.Z.E. Jaafar, A. Rahmat and S. Ashkani, BMC Complementary Alternative Medicine, 15, 335(2015), DOI:10.1186/s12906-015-0838-6

18. E. D. L. Putra, N. Nazliniwaty, F. R. Harun and N. Nerdy, Rasāyan Journal of Chemistry, 13(2), 968(2020), DOI:10.31788/RJC.2020.1325645

19. S. Shiyan, T. Hertiani, R. Martien and A.K. Nugroho, Rasāyan Journal of Chemistry, 12(3), 1098(2019), DOI:10.31788/RJC.2019.1235276

[RJC-5723/2020] 